\title{
A non-invasive screening study of varnishes applied to three paintings by Edvard Munch using portable diffuse reflectance infrared Fourier transform spectroscopy (DRIFTS)
}

\author{
Thierry Ford ${ }^{1,2^{*}} \mathbb{C}$, Adriana Rizzo ${ }^{3}$, Ella Hendriks ${ }^{4}$, Tine Frøysaker ${ }^{2}$ and Francesco Caruso 2,5
}

\begin{abstract}
The availability and popularity of portable non-invasive instrumentation for the study of paintings has increased due to a shift away from using micro-invasive techniques. Fourier transform infrared spectroscopy (FTIR) is a successful and established technique for the characterisation of organic materials in varnish coatings and paint films. In addition, portable FTIR (pFTIR) spectrometers allow for non-invasive in situ analyses. This overcomes the disadvantages associated with micro-sampling and reproducibility issues encountered in analysis at a specific spot, as pFTIR enables examination of the whole painting. However, the practical applications and capabilities of pFTIR as a suitable screening method for the chemical characterization of varnish coatings in painting collections require systematic evaluation. This study involves a selection of three paintings from the collection of 57 works by Edvard Munch belonging to The National Museum of Art in Norway. Its focus is the identification of the non-original varnish types that were applied by the museum. Between 1909 and 1993, the Museum was embroiled in a varnish controversy due to their application of, first natural and then synthetic, varnish coatings to 48 of these Munch paintings. A series of public debates arose about the Museum's varnishing practice, which ran counter to the artist's usual custom of leaving paint surfaces unvarnished (or occasional locally varnished). The three paintings were screened using a pFTIR spectrometer. Different regions of the varnished and unvarnished painted surfaces were analysed with Portable Diffuse Reflectance Infrared Fourier Transform Spectroscopy (DRIFTS). These paintings date from 1887 to 1891 and are documented as having been treated at the Museum with one of the following types of natural or low-molecular-weight synthetic varnish coatings: dammar, mastic, polycyclohexanone (Laropal K 80 from BASF) and reduced or hydrogenated cyclohexanone-co-methyl-cyclohexanone (MS2A from Howards of Ilford). Surface microscopy and multispectral imaging of the varnished surfaces initially assisted the mapping and choice of areas relevant for the portable DRIFTS measurements. Portable X-Ray fluorescence and surface gloss readings were also made at the pFTIR spot locations to complement the results. Using known dry varnish samples, pFTIR reference spectra were obtained and a DRIFT spectral library was also created from known historic batches of varnishes used by the museum. These were then compared with the in situ pFTIR surface readings taken from the paintings together with additional spectra acquired from a selected number of micro-samples from the same spot locations. The preliminary measurements provided an insight into the capabilities, limitations and practical aspects of using portable DRIFTS for the identification of varnish coatings present in this specific selection of Munch paintings.
\end{abstract}

Keywords: Portable FTIR, Varnish coatings, Painting collections, Practical applications, 1887-1891

\footnotetext{
*Correspondence: thierry.ford@nasjonalmuseet.no

${ }^{1}$ The National Museum of Art, P.O. Box 7014, St. Olavs Plass, 0130 Oslo,

Norway

Full list of author information is available at the end of the article
} 


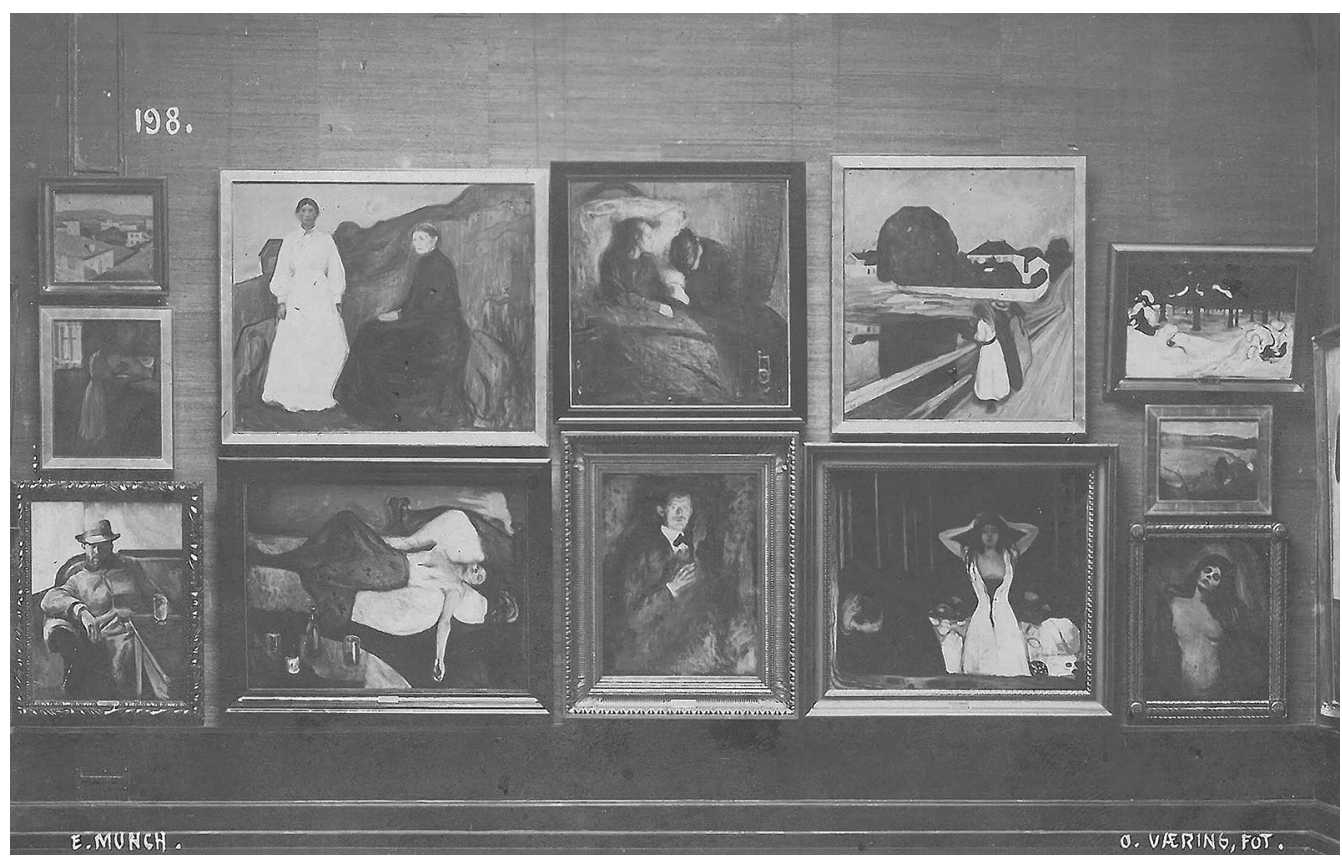

Fig. 1 The National Gallery, Oslo:'The Munch Wall'. Postcard published 1909. (O. Væring, Nils Messel)

\section{Introduction}

The National Museum of Art (NM) in Oslo, Norway, houses one of the largest and the most important single collections by the expressionist artist Edvard Munch (1863-1944). ${ }^{1}$ It comprises 57 paintings from Munch's earlier period and the bulk of the collection was acquired within a 30-year period (1908-1938) by the museum's first director, Jens Thiis (1908-1941) [1]. In June 1909, J. Thiis reopened the newly refurbished South wing of the former National Gallery of Art and set a precedent in terms of how the Munch paintings should be presented and displayed in the museum. A selection of the newly acquired Munch paintings was hung together on a single wall in the East galleries (Fig. 1) and J. Thiis made no secret of the fact that Munch's paintings deserved to be displayed as an ensemble and, ideally, in one room dedicated to the artist [1].

His desire was finally fulfilled in 1937 with the creation of 'The Munch Room' where an ensemble of 18-20 Munch paintings have hung to the present day [2]. This display legacy, viewing the Munch paintings as a group and in one room, will also be re-created in the new NM building, opening in 2020 [3]. In addition to this specific set of display policies, the paintings have been intertwined with a controversial conservation history in terms

\footnotetext{
${ }^{1}$ Since 2003, the former collection of The National Gallery of Art is now part of the National Museum of Art.
}

of varnish coatings. J. Thiis' 1909 re-hanging sparked a critical press review, directed primarily at recent varnish treatments of some of the Munch paintings, described as 'vandalism' [4]. Despite the critique, the museum continued with the contested practice of applying and re-applying natural and synthetic varnish coatings to the Munch collection for a period of 80 years, attracting further criticism [5].

Recent research documents Munch's painting technique but it also points out the need to clarify remaining aspects relating to varnish on the artist's paintings [6, 7]. According to Stein et al. [5] Munch's own attitude to varnishing is unclear due to the ambiguity from the artist's correspondence, contemporary critical sources and the lack of surviving original varnish layers. In general, Munch appears to have favoured matt surfaces with an almost 'fresco-like' finish [8, 9]. Irrespective of this, Selfportrait with Cigarette (Woll 382) was acquired by the NM in the same year that it was painted, 1895 (Fig. 2). According to the conservation records and recent visual examinations, the painting has an unrestored surface with an original locally applied glossy film, used by Munch to saturate certain passages of colours in the composition [10].

The varnishing of easel paintings plays a critical role in the final and intended visual perception of an artwork. Traditional picture varnishes are often complex mixtures and have been classified throughout the history of easel paintings as being either a drying oil without the addition 


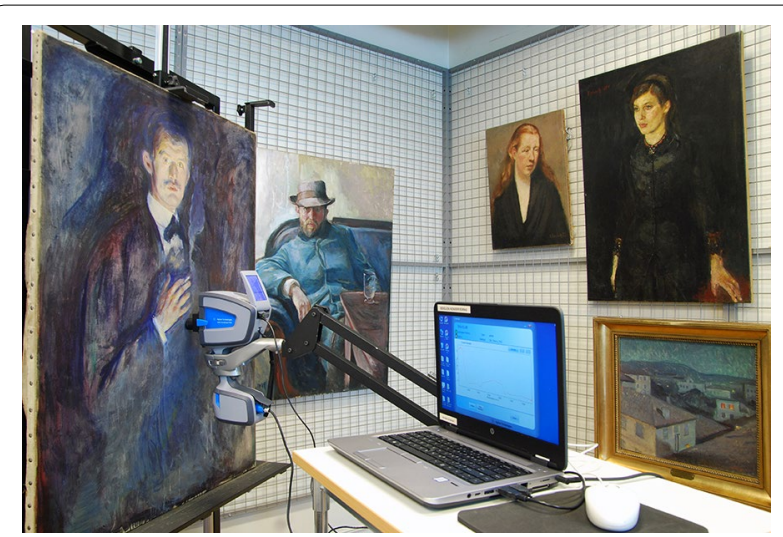

Fig. 2 pFTIR set up at NM conservation studios, Self-portrait with Cigarette (Woll 382)

of resin, an egg white mixture, an oil-resin varnish (a heated natural resin and drying oil mixture) or a solvent/ spirit type (a dissolved resin in a volatile solvent) [11, 12]. The varnishes induce physical changes to the surface topography, refractive index (gloss) and saturation of oil paint layers underneath [13]. In addition, the intrinsic chemical degradation and discolouration of these varnishes pose ethical dilemmas concerning conservation decisions associated with varnish removal (cleaning) and re-varnishing [14].

Acquiring a thorough understanding of the chemical nature of non-original varnish coatings applied to paint surfaces is imperative for devising tailored cleaning strategies. This is particularly relevant for the treatment of larger groups of paintings by a single artist when displayed together, where the visual interrelationships regarding surface gloss and the subtlety of reflected hues play an important role. Traditionally, a variety of laboratory-based analytical methods, including Fourier transform infrared spectroscopy (FTIR), are successfully used for the molecular characterisation of organic compounds, such as those present in varnish coatings [15-18]. However, most of these approaches remain micro-invasive, thus requiring physical sampling from an artwork (albeit involving the removal of non-original material). Recent studies have shown the benefits of portable FTIR spectrometers (pFTIR), which allow for a non-invasive in situ analysis of painted surfaces $[19,20]$. This method of analysis further overcomes the restrictive disadvantages associated with micro-sampling that-when allowed-is often limited to a specific spot [21]. In fact, the pFTIR instrument enables systematic and repeated examination from multiple spots on paintings.

This study is concerned specifically with the evaluation of pFTIR as a viable analytical method for the characterisation of the disputed varnishes types applied to an ensemble of Munch paintings at the NM. Given the complex morphology and topography of varnished paint surfaces, the study evaluates how effectively pFTIR can be used to identify some of the known varnish types and/ or to distinguish between a natural and synthetic resin. In addition, the work addresses the practical context of the technique for conservators in terms of the possibilities and limitations of the equipment as a viable, noninvasive screening method for varnish identification in this collection.

A selection of three varnished Munch paintings were chosen for the study, Flower Meadow Field (Woll 148), Portrait of Hans Jeeger (Woll 174) and Night in Nice (Woll 224). The paintings were carefully selected to provide a degree of consistency according to the following criteria: (i) early creation date; (ii) early acquisition; (iii) solid information about the provenance (some having been purchased from the artist himself); (iv) a minimal record of restoration treatments; (v) a visually noticeable varnish coating. Conservation dossiers note that the portrait of Munch's bohemian friend and author, Hans Jeeger (Woll 174), was last treated in 1954 with mastic varnish, whilst a synthetic coat of varnish polycyclohexanone (Laropal K 80 from BASF) had been applied in 1983 to the other two works [22-24].

\section{Materials and methods}

Research methods included a survey of the NM's conservation records, backdating from the 1950s, and incorporated surviving documentation of past varnishing recipes. Given that no analytical identification of the various varnish types had been previously undertaken across the whole Munch collection, this documentary information provided a basis for establishing an initial overview of the NM's historical varnishing practice and the types of resins used.

\section{Imaging techniques}

Close observation of the paint surfaces and their condition was first carried out using a Leica Wild M8 stereomicroscope $(5 \times$ to $50 \times$ magnification range) (Ortomedic AS, Lysaker, Norway). Raking light photography was employed to study surface topography. Examination with UVA-induced fluorescence photography of the paint surfaces was undertaken to map the distribution of the varnish layers and to assist with the relevant selection and recording of the pFTIR spots. Care was taken to employ photographic standards for the UVA imaging, as advocated by the CHARISMA user manual [25]. A Hasselblad H6D-400C MS digital camera (Interfoto AS, Oslo, Norway) with a Baader UV/IR Cut/L-Filter (Baader Planetarium, Mammendorf, Germany) was used in conjunction with a Target-UV calibration patch (Image 
Science Associates, LLC, Williamson, NY, United States) to control colour and intensity of UVA-induced visible fluorescence. Two UVA luminaires were placed at equal distance, on either side of the painting, with three $40-\mathrm{W}$ UVA fluorescent tubes per luminaire, radiating in the 355-360 $\mathrm{nm}$ region. Infrared reflectography (IRR) with false colour was also carried out to help characterise the distribution of possible infrared transparent pigments (ARTIST camera by the former Dutch company ART Innovation, IR spectral range $700-1100 \mathrm{~nm}$ ). Where possible, the characteristic colouration of certain pigments excited by the UVA-radiation (which induces visible light fluorescence), assisted the portable X-Ray Fluorescence (pXRF) spectral results for pigment identification.

\section{pFTIR}

In situ spectra were acquired in diffuse reflectance (DR) with the 4300 handheld FTIR spectrometer by Agilent (Matriks AS, Oslo, Norway), equipped with a deuterated triglycine sulfate detector and spot size of $6 \mathrm{~mm}$ in diameter. In order to evaluate the reproducibility of the approach, multiple readings were taken in the same spots at different times. DR spectra were plotted in pseudo-absorbance $(\mathrm{y}$-axis $=\log (1 / \mathrm{R}))$ and were acquired between 650 and $4000 \mathrm{~cm}^{-1}$ by accumulating 256 scans (with 8 background scans) at a resolution of $4 \mathrm{~cm}^{-1}$. With this configuration, a high signal to noise ratio was obtained. The spectra were processed with OMNIC Spectra software (version 7.2 by Thermo Fisher Scientific, Oslo, Norway) without the use of correction algorithms. Due to the fragile nature of the paint surfaces and weight of the pFTIR instrument $(2.2 \mathrm{~kg})$, the latter was fitted to a movable counterweight stand. This facilitated control and mobility across the painted surfaces, stability for long acquisition times, whilst also significantly reducing the risk of damage to the artwork. Paintings were secured onto a movable and height-adjustable easel, which allowed for a direct but controlled perpendicular surface contact, required for the spectral reading (Fig. 2).

\section{Reference materials}

A reference library was first created using DRIFT spectra together with the NM's still extant historic solvent varnish mixtures and replicated recipes. The following types of natural and low-molecular weight synthetic varnish coatings were characterized: dammar, mastic, polycyclohexanone (Laropal K 80 from BASF) and reduced or hydrogenated cyclohexanone-co-methyl-cyclohexanone (MS2A from Howards of Ilford). New batches of varnishes were made up according to the original NM's recipes and materials sourced from the museum's dry resin stock. Reference spectra were collected from brushapplied and air-dried solutions of the historic varnishes on MirrIR low-e microscope slides for reflective infrared studies (Kevley Technologies, Chesterland, $\mathrm{OH}$, United States). These slides have no interfering absorption between 400 and $4000 \mathrm{~cm}^{-1}$, thus providing clean varnish reference spectra without any signals from the slide substrate (Table 1).

Varnish thickness in paintings varies according to many factors, such as: surface topography, mode of application, and the drying properties of multiple layers. Recent research, on examples of eighteenth and nineteenth century easel paintings, employing optical coherence tomography to visualize and measure the thickness of varnish coatings, observed a variable thickness between around 10 and $100 \mu \mathrm{m}$, dependent on the texture of the paint at a specific location [26]. According to the manufacturer (Agilent) of the pFTIR unit, the radiation penetrates at 250-500 $\mu \mathrm{m}$ when in reflectance and depending on the response in the infrared region of the sample. Given the irregular surface topography and non-uniformity of the three varnished Munch painted surfaces in question, tests were first undertaken to establish an approximate depth of penetration for the pFTIR in DR. A synthetic varnish recipe (Laropal K 80 grade 9 with wax and stand oil) typically used at NM was applied to both rough and smooth glass slides with an adjustable micrometric film applicator (TQC Sheen, Tønsberg, Norway). The practical limits of the micrometric film applicator together with Agilent's claimed depth of penetration range for the pFTIR unit, governed the application of the varnish tests with the following thicknesses: $250 \mu \mathrm{m}, 500 \mu \mathrm{m}, 750 \mu \mathrm{m}$ and $900 \mu \mathrm{m}$. The $\mathrm{Si}-\mathrm{O}-\mathrm{Si}$ stretching from the glass was employed as an approximate marker for the spectral depth-of-penetration test.

\section{Surface gloss measurements}

Surface gloss readings were undertaken at the same pFTIR spot locations in order to investigate the possible influence from different surface topographies on the pFTIR readings. Four measurements were acquired at each spot location using a Horiba IG-331 gloss checker (Labolytic AS, Trondheim, Norway) and the average is reported here. The spot size for the measurements was $6 \times 3 \mathrm{~mm}^{2}$ with an optical angle of $60^{\circ}$.

\section{Micro-sampling}

For the further validation of some of the pFTIR results, spectra were also compared with those obtained from additional microscopic varnish samples. (Table 2). Where possible, care was taken to select micro-samples from the same areas analysed with pFTIR or immediately adjacent to them. When present in the scrapings, microscopic flakes were mounted as cross-sections to clarify stratigraphy. Layers in cross-section were analysed by attenuated 
Table 1 Library of standards for pFTIR. Historic varnish recipes and additives applied to MirrIR low-e microscope slides

\begin{tabular}{|c|c|c|c|}
\hline MirrIR slide & Varnish reference & Additives & NM historic recipe/supplier/comments \\
\hline MirrIR.01 & Test slide_-no varnish & & Control \\
\hline MirrlR.02 & Laropal K 80_-standard varnish solution & Stand oil & $\begin{array}{l}750 \mathrm{~g} \text { resin (BASF) } \\
1200 \mathrm{~mL} \text { white spirit } \\
300 \mathrm{~mL} \text { vegetable turpentine (Talens) } \\
150 \mathrm{~mL} \text {-butylacetate } \\
75 \mathrm{~mL} \text { stand oil (Talens) }\end{array}$ \\
\hline MirrlR.03 & Laropal K 80_-matt varnish solution & Stand oil + microcrystalline wax & $\begin{array}{l}400 \mathrm{~mL} \text { standard varnish solution } \\
1300 \mathrm{~mL} \text { white spirit } \\
90 \mathrm{~g} \mathrm{microcrystalline} \mathrm{wax} \mathrm{(Cosmolloid} \mathrm{H80)} \\
700 \mathrm{~mL} \text { vegetable turpentine (Talens) }\end{array}$ \\
\hline MirrIR.04 & Laropal K 80_-grade 5 varnish & Stand oil + microcrystalline wax & $\begin{array}{l}2 \text { parts per vol. Standard varnish solution } \\
1 \text { part per vol. Matt varnish solution (shiny varnish) }\end{array}$ \\
\hline MirrlR.05 & Laropal K 80-grade 9 varnish & Stand oil + microcrystalline wax & $\begin{array}{l}1 \text { part per vol. Standard varnish solution } \\
1 \text { part per vol. Matt varnish solution (semi-shiny varnish) }\end{array}$ \\
\hline MirrlR.06 & Dammar_-standard varnish solution & & $\begin{array}{l}1 \text { part per vol. resin (Winsor and Newton) } \\
3 \text { parts per vol. white spirit }\end{array}$ \\
\hline MirrlR.08 & Laropal K 80_-standard varnish solution & & $\begin{array}{l}750 \mathrm{~g} \text { resin (BASF) } \\
1200 \mathrm{~mL} \text { white spirit } \\
300 \mathrm{~mL} \text { vegetable turpentine (Talens) } \\
150 \mathrm{~mL} \text { n-butylacetate (no stand oil) }\end{array}$ \\
\hline MirrlR.10 & Stand oil & & Stand oil (Talens) \\
\hline MirrlR.11 & Tinuvin 292 & & Tinuvin 292 (Ciba-Geigy) \\
\hline MirrlR.12 & Microcrystalline wax & & Cosmolloid H80_-melted on slide \\
\hline MirrlR.13 & Mastic standard varnish solution & & $\begin{array}{l}1 \text { part per vol. resin (Lascaux) } \\
3 \text { parts per vol. vegetable turpentine (Talens) }\end{array}$ \\
\hline
\end{tabular}

Table 2 Micro-samples from paintings for comparative benchtop analyses

\begin{tabular}{|c|c|c|c|c|c|c|}
\hline Painting & $\begin{array}{l}\text { Colour code } \\
\text { reference }\end{array}$ & $\begin{array}{l}\text { Documented } \\
\text { varnish type }\end{array}$ & $\begin{array}{l}\text { pFTIR spot sample } \\
\text { area }\end{array}$ & $\begin{array}{l}\text { pFTIR spot } \\
\text { and micro sample } \\
\text { coordinates }(\mathrm{cm})\end{array}$ & Sample type & Analytical method \\
\hline Woll 148 & Gr.02 (green paint) & $\begin{array}{l}\text { Laropal K } 80 \text { grade } 9 \\
\quad(1983)\end{array}$ & $\begin{array}{l}\text { Bottom right-hand } \\
\text { corner-varnish } \\
\text { layer over green } \\
\text { paint }\end{array}$ & L 39.5-B 4.5 & $\begin{array}{l}\text { Micro scraping and } \\
\text { cross-section }\end{array}$ & $\begin{array}{l}\text { ATR-FTIR, THM-GC/ } \\
\text { MS and micros- } \\
\text { copy }\end{array}$ \\
\hline Woll 148 & Bl.01 (blue paint) & $\begin{array}{l}\text { Laropal K } 80 \text { grade } 9 \\
\quad(1983)\end{array}$ & $\begin{array}{l}\text { Left edge-varnish } \\
\text { in sky }\end{array}$ & L 1.5-B 50.5 & $\begin{array}{l}\text { Micro scraping and } \\
\text { cross-section }\end{array}$ & $\begin{array}{l}\text { ATR-FTIR, THM-GC/ } \\
\text { MS and micros- } \\
\text { copy }\end{array}$ \\
\hline Woll 148 & Bl.02 (blue paint) & $\begin{array}{l}\text { Laropal K } 80 \text { grade } 9 \\
\quad(1983)\end{array}$ & Mid sky_-varnish & L 12.5-B 54 & Micro scraping & $\begin{array}{l}\text { FTIR and THM-GC/ } \\
\quad \text { MS }\end{array}$ \\
\hline Woll 224 & V.06 (blue/red paint) & $\begin{array}{l}\text { Laropal K } 80 \text { grade } 9 \\
\quad(1983)\end{array}$ & $\begin{array}{l}\text { Blue/red paint right } \\
\text { side with varnish }\end{array}$ & L 32-B 3.5 & $\begin{array}{l}\text { Micro scraping and } \\
\text { cross section }\end{array}$ & $\begin{array}{l}\text { ATR-FTIR, Raman, } \\
\text { THM-GC/MS and } \\
\text { microscopy }\end{array}$ \\
\hline
\end{tabular}

L indicates the distance from the left edge. $B$ indicates the distance from the bottom edge

total reflection (ATR)-FTIR. When samples featured residues of underlying paint, Raman micro-spectroscopy (785 $\mathrm{nm}$ laser excitation) was used for pigment identification, in support of pFTIR and pXRF results.

\section{ATR-FTIR and FTIR}

For ATR-FTIR, layers in cross-section were analysed through the $20 \times$ ATR germanium-crystal objective of a
Hyperion 3000 microscope, featuring a liquid-nitrogencooled mercury cadmium telluride detector, and interfaced to a Tensor 27 spectrometer (both instruments by Bruker Optics, Billerica, MA, United States). The spectra were acquired as an average of 64 scans in the range from 600 to $4000 \mathrm{~cm}^{-1}$ at a resolution of $4 \mathrm{~cm}^{-1}$. For scrapings, the samples were crushed in a diamond micro compression cell (Spectra-Tech, Inc., Oak Ridge, TN, 
United States) and analyzed using a $15 \times$ FTIR objective using the instrumental set-up and acquisition conditions reported above.

\section{THM-GC/MS}

Further tests using thermally assisted hydrolysis and methylation-gas chromatography coupled with mass spectrometry (THM-GC/MS) were employed for the analysis of selected micro samples. Micro samples with a mass between 15 and $30 \mu \mathrm{g}$ were accurately weighed on an Ultramicrobalance UMX2 (Mettler Toledo, Columbus, OH, United States) in the pyrolysis cup (Eco-cup, Frontier lab, Fukushima, Japan). $3 \mu \mathrm{L}$ of TMAH solution ((tetramethyl)ammonium hydroxide $25 \%(\mathrm{w} / \mathrm{w})$ in methanol) were added to the sample prior to pyrolysis at $550{ }^{\circ} \mathrm{C}$ in the vertical micro-furnace of the double-shot $2020 i D$ pyrolyzer (also from Frontier lab). The micro-furnace is interfaced to the gas chromatograph Agilent 6890 coupled with the Agilent 5973 Network Mass Selective Detector (Agilent Technologies, Inc., Santa Clara, CA, United States). The analysis was carried out in split mode at a split ratio 15:1. An Agilent J\&W DB-5ms capillary column $(30 \mathrm{~m} \times 0.25 \mathrm{~mm} \times 0.25 \mu \mathrm{m})$ was used. The inlet and the MS transfer line were kept at $320^{\circ} \mathrm{C}$. Helium was used as the carrier gas at a constant flow of $1 \mathrm{~mL} / \mathrm{min}$. The GC oven temperature program was: $40{ }^{\circ} \mathrm{C}$ for $2 \mathrm{~min}$, up to $320^{\circ} \mathrm{C}$ with a rate increase of $6{ }^{\circ} \mathrm{C} / \mathrm{min}$, followed by $10 \mathrm{~min}$ of isothermal conditions. Analysis was conducted in full scan mode $(35-600 \mathrm{~m} / \mathrm{z})$. Temperatures at MS source was $230{ }^{\circ} \mathrm{C}$ and at quadrupole $150{ }^{\circ} \mathrm{C}$. A solvent delay of 2 min was used.

\section{pXRF}

pXRF was employed for the surface elemental characterization of some of the pigments present in Munch's paintings. This provided a supplementary non-invasive form of analyses which assisted the interpretation of the pFTIR and the discernment of pigment interference attributable the underlying paints. In addition, it provided information on Munch use of pigments. Measurements were taken with a Thermo Niton XL3t 900 energy dispersive pXRF spectrometer (Thermo Scientific, Holger Hartmann, Oslo, Norway) with a Si-drift detector (GOLDDGeometrically Optimized Large Drift Detector) attached to a tripod. Multiple readings were taken from the same areas analysed by pFTIR or adjacent passages with dominant primary, secondary, black and white colours. The proprietary "Mining $\mathrm{Cu} / \mathrm{Zn}$ Testing Mode" was used. This mode allowed to detect the largest range of elements. Total measurement time was ca. $60 \mathrm{~s}$ for each sampled area and the instrument switched automatically from main (Al/Fe filter, potential: $50 \mathrm{kV}$, maximum current: $40 \mu \mathrm{A}$ ) to low (Cu filter, potential: $20 \mathrm{kV}$, maximum current: $100 \mu \mathrm{A}$ ), high (Mo filter, potential: $50 \mathrm{kV}$, maximum current: $40 \mu \mathrm{A}$ ) and light range filters.

\section{Results and discussion}

Initial findings from the survey of the NM's conservation dossiers revealed that 48 paintings from the total of 57 Munch paintings had a varnish coating and that 30 of these 48 varnished paintings were documented as having been varnished by the NM [27]. The reports also revealed a gradual shift from using traditional natural resin varnishes (post-1950) towards the dominant use of two synthetic types (Laropal K 80 and MS2A) by the mid-1980s. Information from the NM's historic varnish recipes confirmed the use of common additives in small percentages to various mixtures [27]. Microcrystalline wax was included in some recipes to reduce gloss and in some cases a light stabilizer, bis(1,2,2,6,6-pentamethyl-4-piperidyl) sebacate and methyl-1,2,2,6,6-pentamethyl-4-piperidyl sebacate (Tinuvin 292, Ciba-Geigy Marienberg $\mathrm{GmbH}$, Germany), had been incorporated as a preventive method against light ageing [28]. In some cases, the anomalous addition of a heat-bodied linseed oil (stand oil) had also been introduced, possibly to control the application process, saturation and gloss. Notwithstanding the significance of the documentary information, inconsistencies and variations in recording conservation data between 1949 and 1993 were noted in the dossiers, emphasising the need for a chemically specific form of identification of the varnish coatings.

Depth of penetration tests undertaken in DR on varnish applied to glass slides recorded interference signals from the $\mathrm{Si}-\mathrm{O}-\mathrm{Si}$ stretching from the glass between thicknesses of $250 \mu \mathrm{m}$ and $500 \mu \mathrm{m}$. This helped to establish an approximate depth of penetration range for the detection of Laropal K 80 grade 9 varnish, applied to the paintings.

\section{Flower Meadow Field (Woll 148)}

Munch's small plein air painting, Flower Meadow Field was painted whilst he resided with his family on the island of Veierland, South of Oslo in the summer of 1887 [8]. The composition $(66.5 \mathrm{~cm} \times 44 \mathrm{~cm})$ donated to the museum in 1921 has been executed rapidly with thick brush strokes and raised impasto on a relatively thin white ground layer. Evidence of early framing marks in the wet oil paint can be seen around all four edges of the composition and the thinly woven canvas support has been later marouflaged onto a cardboard support. Conservation dossiers only record the application of Laropal K 80 grade 9 varnish in 1983 [24]. The purple coloured fluorescence emitted under UV and the stereomicroscopic investigations confirmed the presence of a thick, 


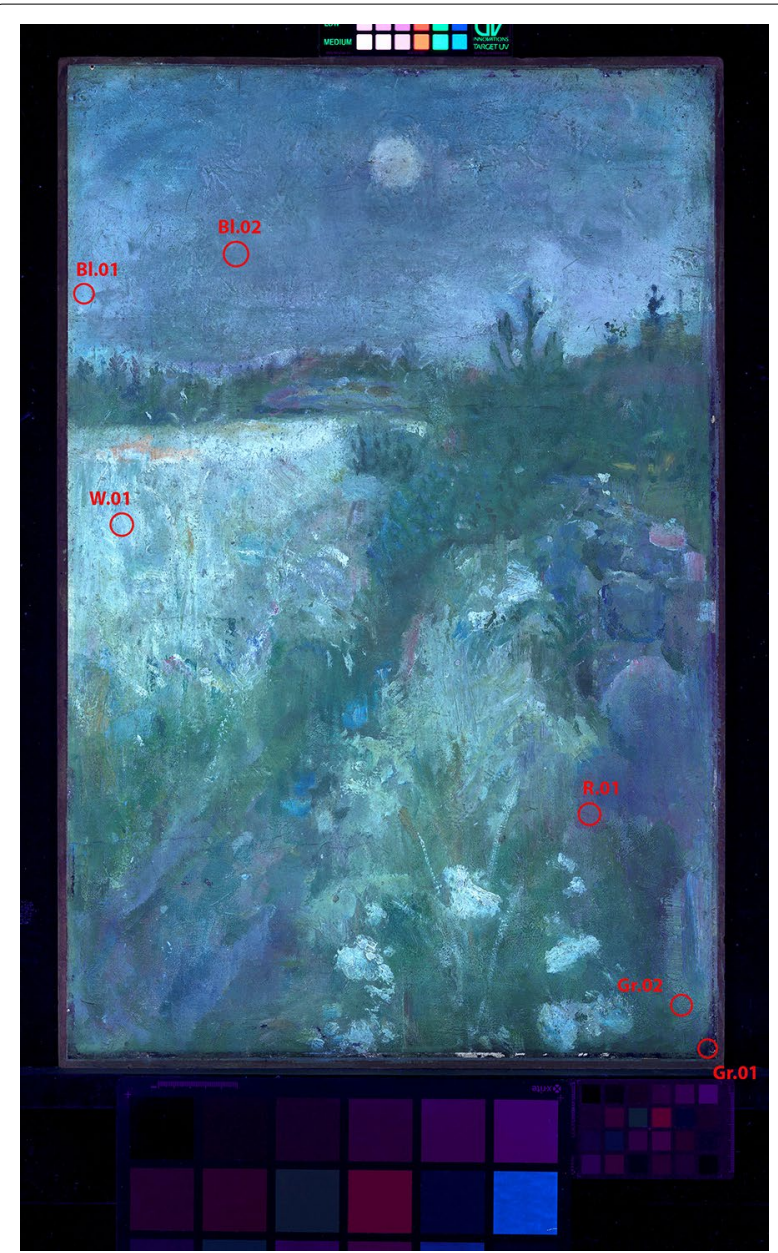

Fig. 3 Flower Meadow Field (Woll 148), UVA-induced fluorescence photography, showing fluorescence of the upper varnish coating and pFTIR spot locations

discoloured (yellowing) and evenly distributed top varnish layer (Fig. 3).

pFTIR spectral readings were taken from four different coloured areas with varnish (Green Gr.02, Blue Bl.01, Bl.02, White W.01 and Red R.01) and one green spot without (Gr.01, old cleaning test). Spectra obtained from all the varnished areas showed intense peaks related to the aliphatic $\mathrm{C}-\mathrm{H}$ stretching band around $2857 \mathrm{~cm}^{-1}$ and $2945 \mathrm{~cm}^{-1}$. These, together with the strong peaks noted at $1451 \mathrm{~cm}^{-1}$ and $1712 \mathrm{~cm}^{-1}$, in the green (Gr.02) and red (R.01) pigmented areas, appear to be in line with spectral features of the synthetic resin Laropal K 80 [29] (Fig. 4). For quantifying the reproducibility of the measurements, the coefficient of variation (CV) of the wavenumbers of three independent readings carried out at different times was calculated on different bands (stretching bands of $\mathrm{OH}, \mathrm{CH}_{2}-\mathrm{CH}_{3}, \mathrm{C} \equiv \mathrm{N}$ and $\mathrm{C}=\mathrm{O}$ ). This ranged from $0.027 \%$ for the $\mathrm{CH}_{2}-\mathrm{CH}_{3}$ peaks centred at around $2930 \mathrm{~cm}^{-1}$ to $0.695 \%$ for the same bands. This shows a very good reproducibility of the measurements. When relating gloss measurements with the quality of the spectra obtained, a slightly lower value, 8-10 GU, was observed in the varnished green (Gr.02) and red (R.01) areas compared to those noted in the varnished white and blue areas (12-14 GU). In raking light, the surface topography of the paint in the blue sky and white meadow regions revealed a slightly smoother (glossier) surface compared to the more irregular topography from the impasto in the green and red passages of paint. Significantly lower surface gloss measurements (1-2 GU) were recorded in the unvarnished and matt area (Gr.01) and its pFTIR spectrum, plotted with the adjacent varnished area (Gr.02), recorded a definite reduction of the bands around $2854 \mathrm{~cm}^{-1}$ and $2940 \mathrm{~cm}^{-1}$ (Fig. 5). This confirms that the synthetic Laropal K 80 varnish layer had been removed or reduced to undetectable in the Gr.01 area, after cleaning. Supplementary micro-invasive analysis by THM-GC/MS confirmed the presence of Laropal $\mathrm{K} 80$ in the Gr.02 area. Synthetic resin, and additionally detected components of dammar resin, probably from a previous unrecorded varnish application, as well as a substantial amount of siccative oil, which could have migrated from the paint to the varnish layer [30] (Fig. 6).

The prominent peak at $2088 \mathrm{~cm}^{-1}$ noted in many of the spectra could be attributed to the $\mathrm{C} \equiv \mathrm{N}$ stretching associated with the pigment Prussian blue from the paint layer [31]. The presence of a stretching band at $3545 \mathrm{~cm}^{-1}(\mathrm{OH})$ and a stronger one around $1450 \mathrm{~cm}^{-1}$ (carbonate stretching) in the red area (R.01) indicate also the presence of lead white $\left(2 \mathrm{PbCO}_{3} \cdot \mathrm{Pb}(\mathrm{OH})_{2}\right)$ in that coloured paint.

The identification of the various pigments was difficult to ascertain by their colouration under UVA examination alone, given the overriding and dominant fluorescence of the varnish coatings present. The diffuse presence of lead in all the pXRF readings helped to confirm the use of lead white throughout. Mercury was identified in passages with red paint and implied a palette containing vermillion whilst the iron peaks noted in the XRF spectra of the blue sky helped to further confirm the pFTIR finding for Prussian blue. The presence of chromium recorded in the green areas combined with the dark character (UVA-absorbing) of the unvarnished green area (Gr.01) in UVA light, suggested the use of a chromium green oxide based pigment [32]. Peaks for cadmium and iron were detected in the XRF spectra from various passages of yellow paint and indicated the use of both cadmium yellow and yellow earth, respectively. 


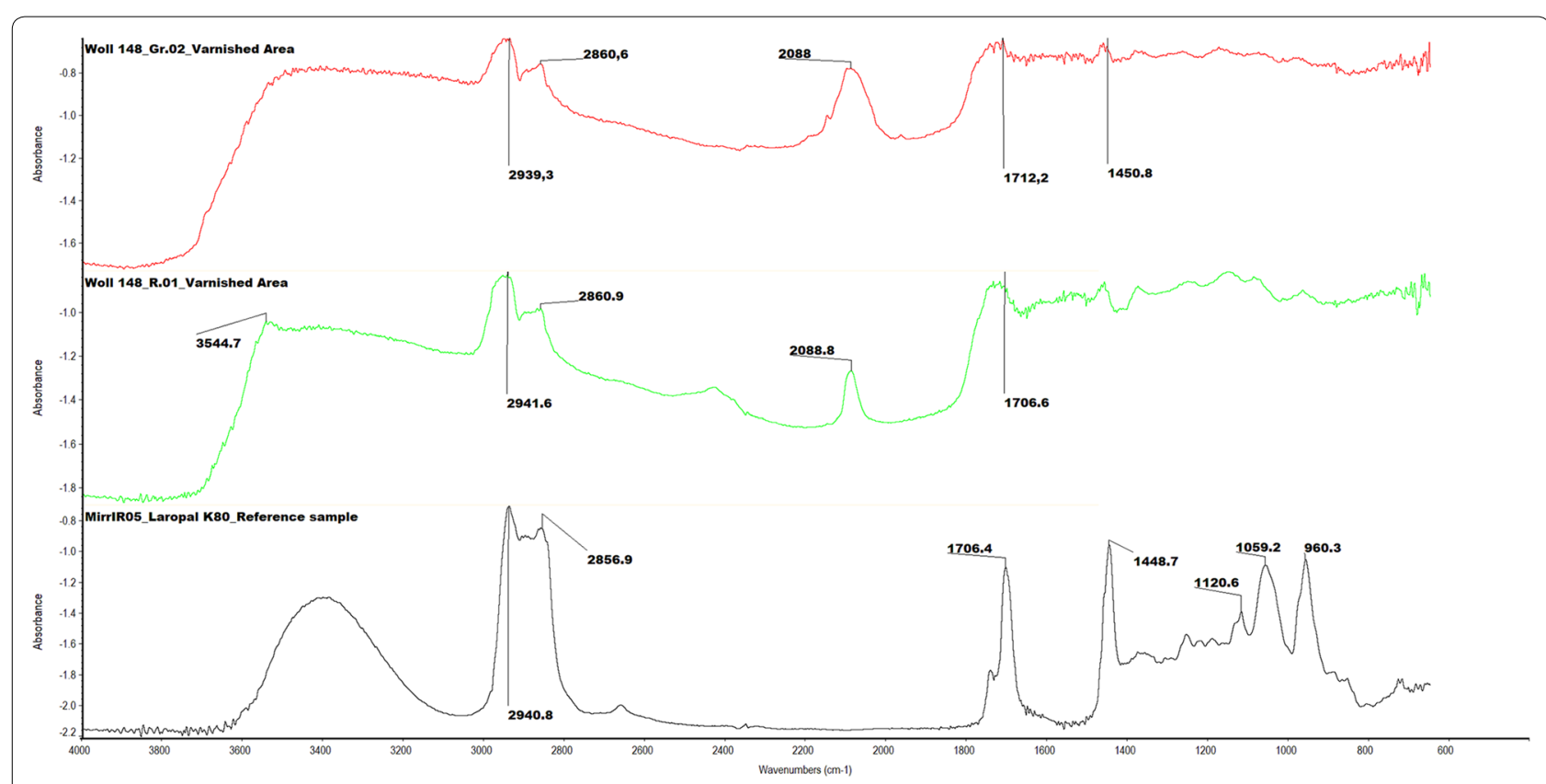

Fig. 4 Portable DRIFT spectra for readings from green and red varnished paint passages (Gr.02 and R.01) and Laropal K 80 grade 9 varnish reference (MirrlR.05), Flower Meadow Field (Woll 148)

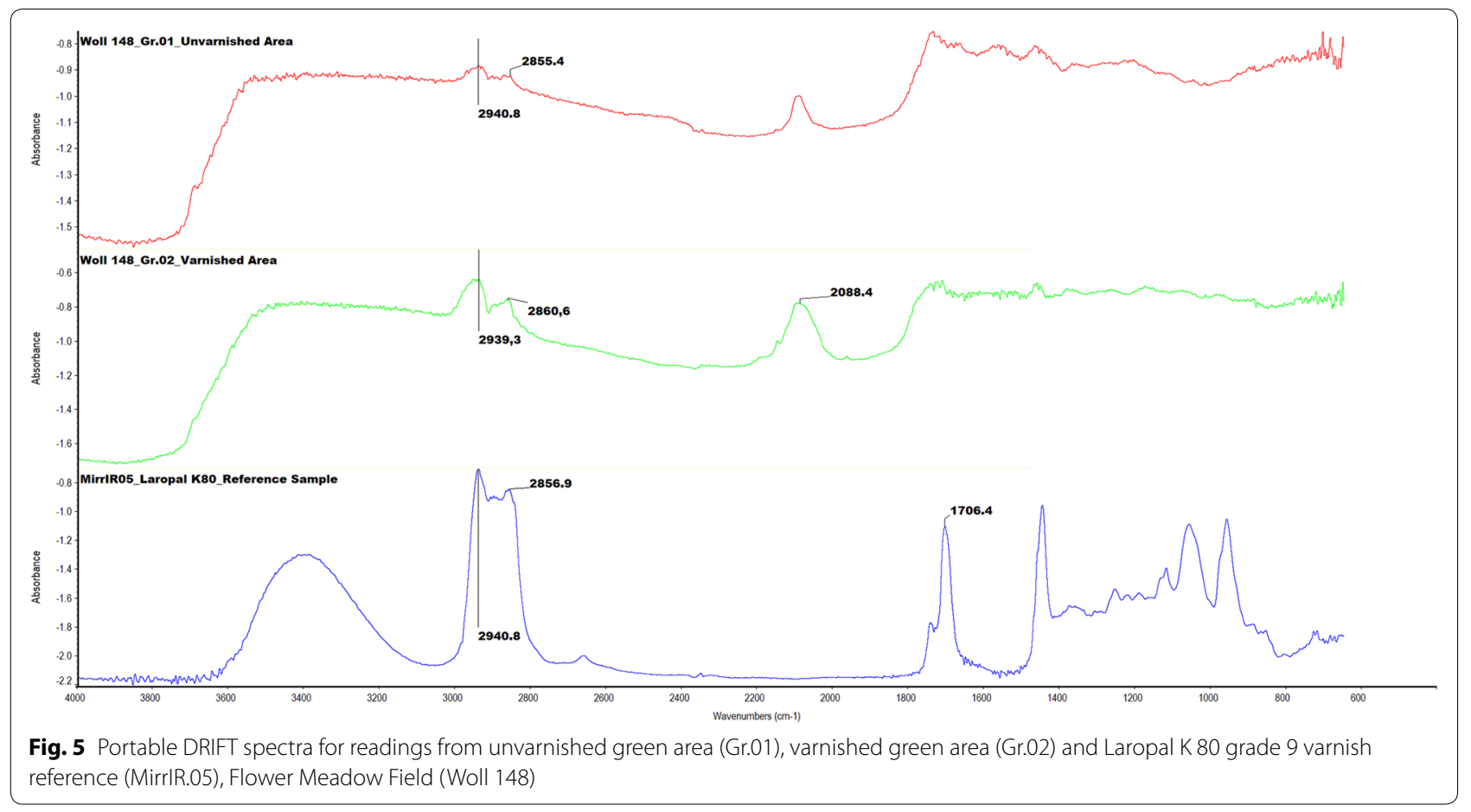

\section{Portrait of Hans Jæger (Woll 174)}

Munch painted the portrait of his friend, the bohemian author Hans Jæger (1854-1910), in March/April of 1889 and the painting $(109 \mathrm{~cm} \times 84 \mathrm{~cm})$ was owned by Munch until it was purchased by the NM eight years later. Conservation dossiers only mention one major restoration carried out in 1954 when it was cleaned, gluepaste lined and varnished with mastic [22]. Like Flower Meadow Field, the paint application is thick with little exposed ground. 


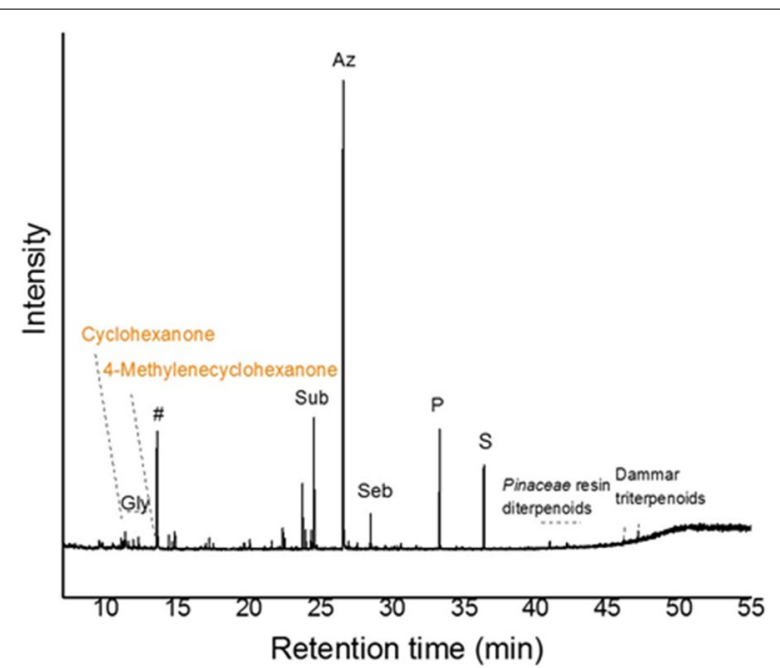

Fig. 6 Total ion chromatogram obtained from THM-GC/MS of varnish scrapings (Gr.02) from Flower Meadow Field (Woll 148). Laropal K80 markers: cyclohexanone and 4-methylcyclohexanone. The drying oil was detected based on the distribution of the methyl esters of fatty acids. Sub suberic, Az azelaic, Seb sebacic, P palmitic, S stearic, gly methyl esters and glycerol. \#: reagent peak

UV photography confirmed the presence of a varnish coating with a dull yellowish, green fluorescence evenly applied throughout (Fig. 7). pFTIR spot readings were taken from different areas, the blue coat (Bl.01 and Bl.02), white background (W.01 and W.02), red/pink flesh tints (R.10), the dark red/brown wood colour from sofa (R.01R.09) and the yellow paint along the top edge (Y.01). Marked spectral differences were observed between the different coloured areas. The spectra for the reddish/ brown spots (R.01) showed intense peaks at $2849 \mathrm{~cm}^{-1}$ and $2918 \mathrm{~cm}^{-1}$ (Fig. 8). The shapes of the aliphatic $\mathrm{CH}$ stretching bands suggested the presence of an oil-natural resin rather than a synthetic one. Moreover, the spectra contained similarities to the mastic reference sample with the association of the carbonyl band at $1740 \mathrm{~cm}^{-1}$ with an oil-resin. In contrast, spectral readings taken from the white painted areas (W.01 and W.02) had strong signals typically associated with presence of lead white in the paint layers with an $\mathrm{OH}$ band at $3540 \mathrm{~cm}^{-1}$ and the broad carbonate band at about $1450 \mathrm{~cm}^{-1}$ [33]. This made it difficult to assign spectral characteristics associated with a specific resin varnish. As with Flower Meadow Field, for quantifying the reproducibility of the measurements, the $\mathrm{CV}$ of three independent readings carried out at different times was calculated on different bands (stretching bands of $\mathrm{OH}, \mathrm{CH}_{2}-\mathrm{CH}_{3}, \mathrm{C} \equiv \mathrm{N}$, and $\mathrm{CO}_{3}{ }^{2-}$ ). This ranged from $0.010 \%$ for the $\mathrm{CO}_{3}{ }^{2-}$ peaks centred at around $1450 \mathrm{~cm}^{-1}$ to $0.653 \%$ for the $\mathrm{CH}_{2}-\mathrm{CH}_{3}$ stretching bands centred at around $2950 \mathrm{~cm}^{-1}$. Again, this showed a very

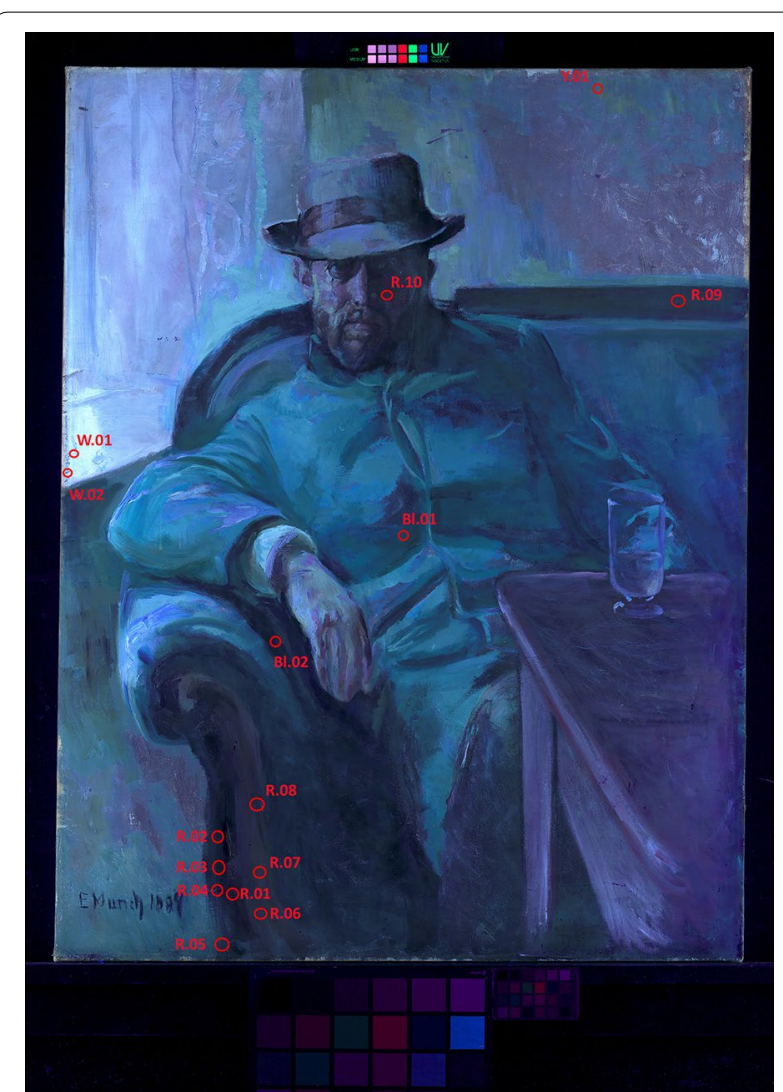

Fig. 7 Portrait of Hans Jæger (Woll 174), UVA-induced fluorescence photography, showing fluorescence of the upper varnish coating, pigment differences and pFTIR spot locations

good reproducibility of the pFTIR measurements. Surface gloss measurements revealed higher values recorded in the smoother surface topography of the white regions (17-22 GU) compared to those from the irregular surface topography of the textured brush strokes in the reddish/ brown areas (4-8 GU). As noted in the painting, Flower Meadow Field, the clarity of the spectra for varnish resin identification appeared to be influenced by its thickness, surface texture, and pigment composition. A similar low 1-2 GU range was also recorded in unvarnished regions, along the painted tacking edges.

X-radiographs taken in 1993 revealed that Munch had extensively re-worked the bottom right-hand corner of the composition, the table, and had also undertaken some minor alterations to the sitter's seated position by lowering the right-shoulder, arm and hand [34]. In contrast to Flower Meadow Field, the distinctive colouration of certain pigments, when illuminated by UVA radiation, could be detected. Two different types of white pigment, lead white and zinc white, appear to have been used by Munch, possibly in relation to the compositional process and later alterations. In the passages of white paint 


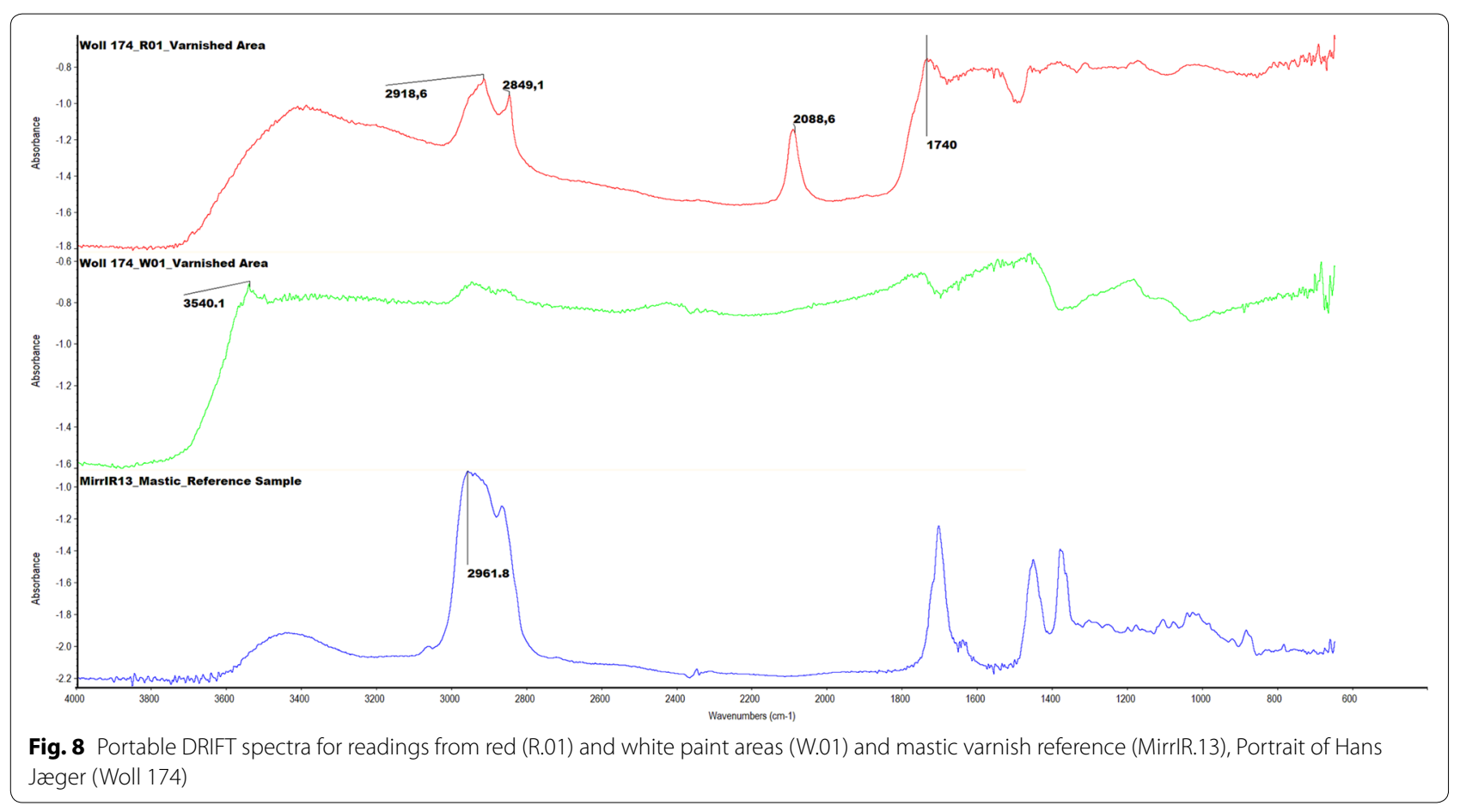

and pigment mixtures, a difference between the characteristic reddish-purple UVA-fluorescence colouration of lead white and the opaquer greenish-yellow colouration associated with zinc white was noted [32]. The presence of lead and zinc was further supported by pXRF. A typical dark blue UVA-induced fluorescence witnessed in the blue region (Bl.02), combined with traces of iron detected by pXRF, helped to confirm the presence of Prussian blue. Vermillion was also probably identified using pXRF through the presence of mercury.

\section{Night in Nice (Woll 224)}

The NM's first Munch acquisition is the small painting, Night in Nice $(40 \mathrm{~cm} \times 54 \mathrm{~cm})$, which was purchased from the autumn state art exhibition (Høstutstillingen-Statens Kunstutstilling) in the same year as it was painted, 1891 [1, 2, 8]. As an early work, Munch's painting technique is relatively traditional in terms of paint application. The build-up is simple compared to the two other works examined, thinly executed and with no distinct raised impasto or surface textural effects. Part of the motif is present on the lower tacking edge and a canvas stamp with no. 15 on the reverse indicates a French commercial standard format of $65 \mathrm{~cm} \times 54 \mathrm{~cm}$. The canvas has been later reduced (cut) in height from 65 to $48 \mathrm{~cm}$ by the artist and stretched onto a smaller stretcher. According to the conservation records, a coat of Laropal K 80 grade 9 varnish was sprayed over the paint surface in 1983 after a light surface cleaning [23]. The presence of varnish was confirmed by the strong yellow/green coloured fluorescence under UVA examination (Fig. 9).

Closer microscopic examination further confirmed a varnish coating that does not extend to all four edges of the canvas. Moreover, drip marks in the varnish along the lower canvas edge appear to correspond precisely

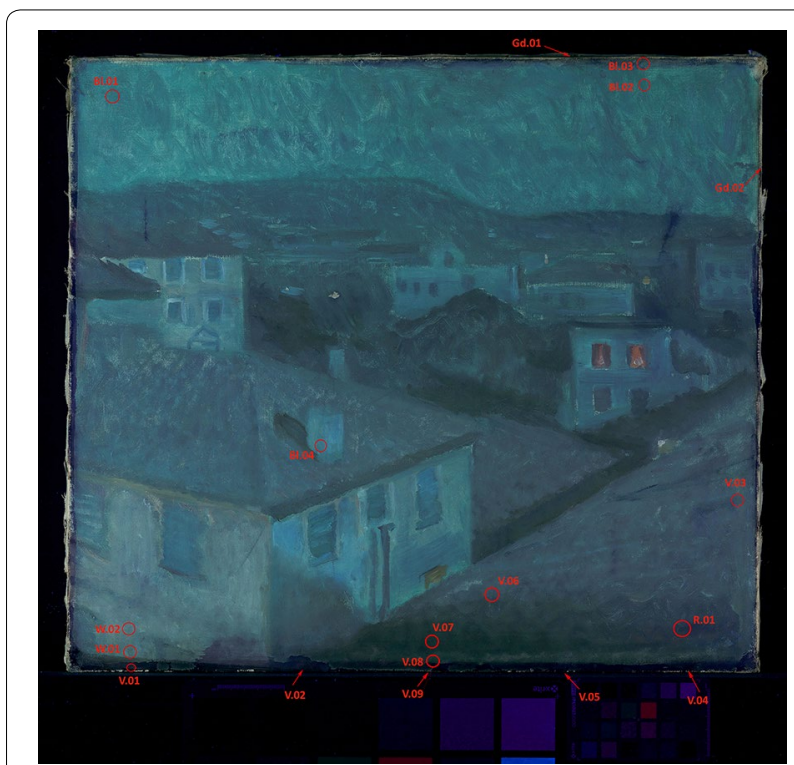

Fig. 9 Night in Nice (Woll 224), UVA-induced fluorescence photography, showing fluorescence of varnish and pFTIR spot locations 


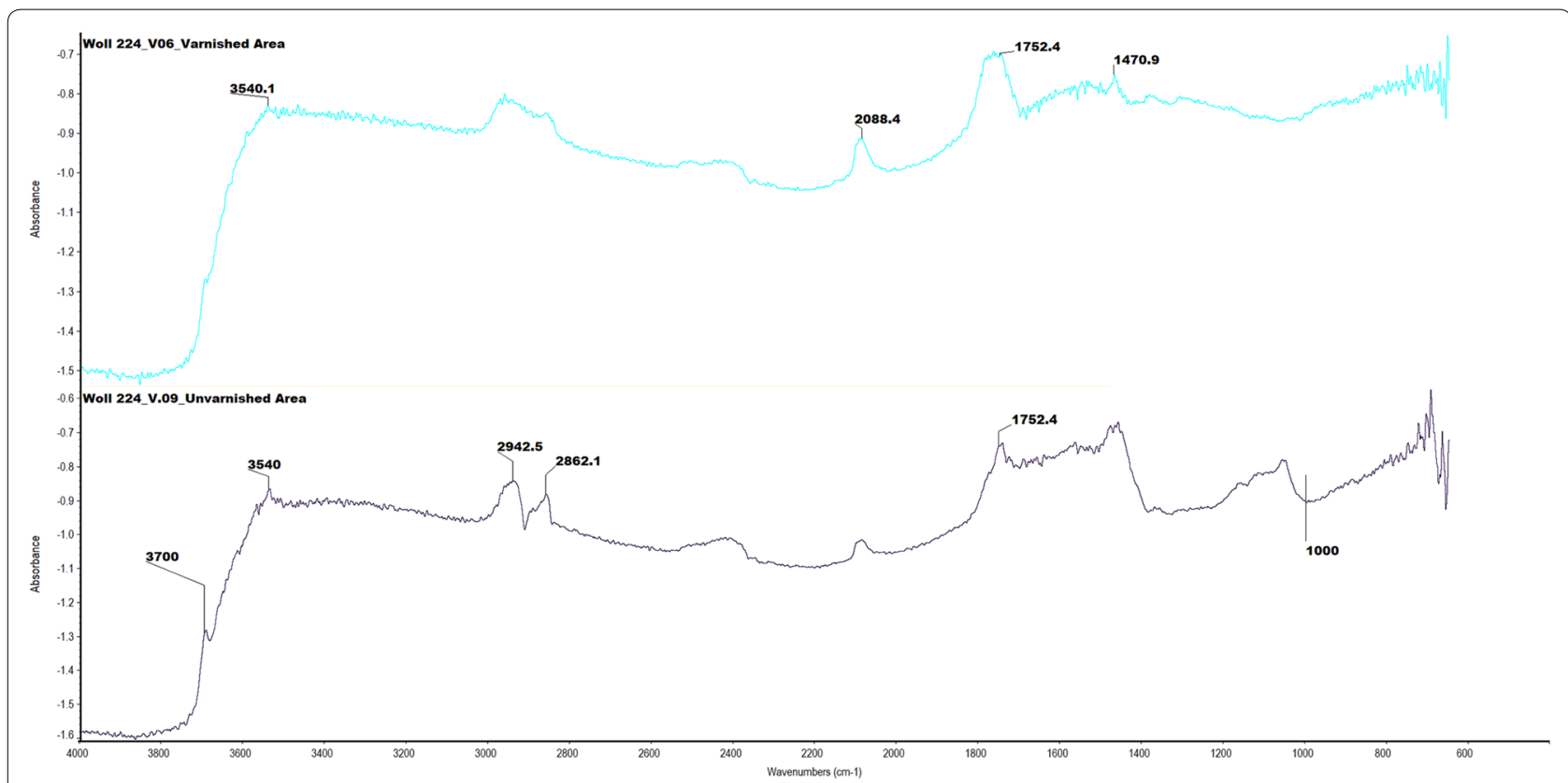

Fig. 10 Portable DRIFT spectra for readings from blue/red paint spots (V.06 and V.09), Night in Nice (Woll 224)

with a fluorescence pattern detected under UVA light along the lower inner sight-edge of the original frame. These findings confirmed the presence of an earlier and previously undocumented varnish layer underneath the aforementioned thinly applied synthetic varnish (Laropal K 80 grade 9) recorded from 1983. It is possible that this varnish was directly applied whilst the canvas was still in its frame. In situ pFTIR measurements were recorded over different coloured areas of blue $(\mathrm{Bl})$, violet $(\mathrm{V})$, white $(\mathrm{W})$ and red (R), and along the lower unvarnished tacking margin including areas with exposed ground (Gd) (Fig. 9). Preliminary results captured characteristic spectral features for lead white with typical absorptions for $\mathrm{OH}$ bond at $3540 \mathrm{~cm}^{-1}$ and for carbonate around $1470 \mathrm{~cm}^{-1}$, predictably more prominent in the unvarnished areas [33] (Fig. 10).

As in Flower Meadow Field, the reoccurring prominent peak at $2088 \mathrm{~cm}^{-1}$ present in many of the spectra could be associated with the presence of Prussian blue in the underlying paint. However, no bands typical of a synthetic Laropal K 80 resin, allegedly applied to the surface in 1983, were detected in any of the spectra. As noted by Miliani et al. [20] caution is required when extrapolating data from the FTIR spectra due to the often-complex stratigraphic character and heterogeneous nature of paint layers and surface coatings, which need to be understood. Comparisons between readings taken from two similarly pigmented areas, one varnished (V.06) and one unvarnished (V.09), revealed some minor spectral differences. In the unvarnished area, sharp derivative inverted bands at $2862 \mathrm{~cm}^{-1}$ and $2942 \mathrm{~cm}^{-1}$, typical of the $\mathrm{CH}_{2}$ and $\mathrm{CH}_{3}$ stretch for an oil, were detected, as was the carbonyl stretch at around $1752 \mathrm{~cm}^{-1}$. In the varnished area, the absorptions for the $\mathrm{CH}_{2}$ and $\mathrm{CH}_{3}$ stretch are relatively weak. Supplementary micro-invasive analysis was thus undertaken for clearer identification of the varnish coatings. The presence of Prussian blue was confirmed with ATR-FTIR and Raman analyses (V.06) and further tests using THM-GC/MS confirmed the presence of a drying oil and components of dammar. No Laropal K 80 resin was detected suggesting that either it had been removed post-1983 or that the painting was never actually varnished with it, contrary to the conservation report. Gloss measurements taken from all the varnished pFTIR spot locations recorded values of $12-14 \mathrm{GU}$ and low values (1-2 GU) in the unvarnished regions. The similar high gloss surface readings recorded on the various varnished parts of the paint surface correspond to the painting's relatively flatter surface topography and minimal surface texture. Like with Flower Meadow Field, the identification of the various pigments proved difficult to be ascertained by their colouration under UVA radiation. pXRF helped to confirm the use of lead white, vermillion and cadmium yellow. Traces of iron, associated with Prussian blue, were also detected.

\section{Conclusion}

This study aimed to test the versatility of pFTIR for the surface analysis of non-original varnish coatings on three Munch paintings from the NM's collection. 
pFTIR proved useful for the investigation and further understanding of the historic varnish controversy regarding this specific collection. In two cases, it was possible to align the pFTIR results with information derived from archival sources, but the discrepancy observed with Night in Nice highlighted the need for a reliable and comprehensive methodology for the identification of the varnish coatings. Spectra collected in DR from different passages of paint in all three paintings showed a certain degree of pigment interference. In fact, bands associated with known pigments, such as Prussian blue and lead white, were observed in some of the recorded spectra. A strong pigment interference was especially noted with the more optically flat and glossy surfaces. Yet, marked differences in gloss readings between a matt or irregular surface topography with a glossier, smoother varnished area, also appeared to influence the clarity of the DRIFT spectra. The possible impact of surface topography, varnish thickness and pigment type require further investigation. The integration of historical conservation documentation with visual examinations and pigment identification, remained paramount for pFTIR spectral interpretation as did the creation of a good reference library in DR, comprised of relevant and known varnish recipes. Nevertheless, the typical heterogeneous structure of paint and varnish films often contributed to the acquisition of complex pFTIR spectra. Overlapping bands attributable to compounds from pigments and varnishes restricted the possibility of unambiguously matching DRIFT spectra from paintings with the reference samples. Results from micro-invasive techniques (namely, ATR-FTIR, Raman and THM-GC/MS) were thus necessary for a more decisive validation of the results. Notwithstanding these limitations, it was possible to detect and confirm the presence of Laropal $\mathrm{K} 80$ resin on one of the paintings. The preliminary results further served to evaluate the use of pFTIR as a suitable screening method for the chemical characterization of varnish coatings for the remaining varnished Munch paintings in the NM's collection. As a method for non-invasive and in situ analyses of painted surfaces, it was found to offer several practical and user-friendly advantages for the conservator. These included the benefit of taking unlimited readings from multiple areas, with good reproducibility. A controlled and safe contact was also achieved between the measuring interface and the paint surface for spectral readings. In addition, although the pFTIR equipment is relatively user-friendly to operate, the complexity of interpreting results underlined the importance of collaboration between conservator and scientist. Despite its drawbacks, the use of a portable DRIFTS device notably contributed to the preliminary screening of upper and non-original varnish coatings applied to the three Munch paintings, when used in a multi-analytical context.

\begin{abstract}
Abbreviations
ATR-FTIR: attenuated total reflection infrared Fourier transform spectroscopy; CV: coefficient of variation; DR: diffuse reflectance; DRIFTS: diffuse reflectance infrared Fourier transform spectroscopy; pFTIR: portable infrared fourier transform spectroscopy; GC/MS: gas chromatography-mass spectrometry; GU: gloss units; IRR: infrared reflectography; NM: The National Museum of Art, Norway; THM-GC/MS: thermally assisted hydrolysis and methylation-gas chromatography-mass spectrometry; UVA: ultra violet light between $315 \mathrm{~nm}$ and 400 nm, after ISO 21348 definitions of solar irradiance spectral categories; pXRF: portable X-ray fluorescence spectrometry.
\end{abstract}

\section{Acknowledgements}

The authors are grateful to the National Museum of Art, Norway, for full access to the paintings. The authors would also like to thank Børre Høstland and Duncan Slarke for their assistance with the UV and IRR photography and to the art historian, Nils Messel, for advice on the Munch collection.

\section{Authors' contributions}

TF designed the research and performed the pFTIR experiments. ATR-FTIR, benchtop FTIR, Raman and THM-GC/MS experiments were carried out by AR. $T F, A R$ and FC contributed in analysing and interpreting the data. TF wrote the first draft of the paper. All the authors contributed by interpretation and writing the paper. All authors read and approved the final manuscript.

\section{Funding}

The project is part of Thierry Ford's Ph.D. study, which is fully funded by the National Museum of Art, Norway.

Availability of data and materials

Raw data is available from the authors on request.

\section{Competing interests}

The authors declare that they have no competing interests.

\section{Author details}

${ }^{1}$ The National Museum of Art, P.O. Box 7014, St. Olavs Plass, 0130 Oslo, Norway. 2 Department of Archaeology, Conservation and History (IAKH), Conservation Studies, University of Oslo (UiO), Postboks 1008 Blindern, 0315 Oslo, Norway. ${ }^{3}$ The Metropolitan Museum of Art, 1000 5th Avenue, New York 10028, NY, USA. ${ }^{4}$ Programme Conservation and Restoration of Cultural Heritage, University of Amsterdam (UvA), Johannes Vermeerplein 1, 1071 DV Amsterdam, The Netherlands. ${ }^{5}$ Present Address: Department of Art Technology, Swiss Institute for Art Research (SIK-ISEA), Zollikerstrasse 32, 8032 Zurich, Switzerland.

Received: 19 June 2019 Accepted: 2 October 2019

Published online: 22 October 2019

\section{References}

1. Willoch S. Nasjonalgalleriet gjennom hundre år. Oslo: Gydendal; 1937.

2. Messel N. "Den smakfuldeste dekoratør i Norden"; Jens Thiis i Nasjonalgalleriet. Kunst og Kultur. 2012;95(4):200-17.

3. Borud H. Stor Munchs-satsing i det nye museet på Vestbanen: Det nye Nasjonalmuseet på Vestbanen vil ha et stort eget rom til Edvard Munchs kunst. [Newspaper in line article]. Oslo, Norway: Aftenposten; 2015. https ://www.aftenposten.no/kultur/i/abJa/Stor-Munchs-satsing-i-det-nyemuseet-pa-Vestbanen. Accessed 11 Aug 2019.

4. Rød J. Harald Brun; konservator ved Nasjonalgalleriet 1905-21. Kunst og Kultur. 1993;76(2):89-107.

5. Stein $M, R ø d$ J. A contribution to the varnish history of the paintings by Edvard Munch at the National Museum and Munch Museum, Oslo. In: Frøysaker T, et al., editors. Public paintings by Edvard Munch and his contemporaries Change and conservation challenges. London: Archetype; 2015. 
6. Frøysaker T, Streeton N, Kutzke H, Hanssen-Bauer F, Topalova-Casadiego B. Public paintings by Edvard Munch and his contemporaries. Change and conservation challenges. London: Archetype; 2015.

7. Ormsby B, Frøysaker T, Topalova-Casadiego B. Munch 150: reflections and challenges. In: Frøysaker T, et al., editors. Public paintings by Edvard Munch and his contemporaries change and conservation challenges. London: Archetype Publications; 2015. p. 351-62.

8. Woll G. Edvard Munch, samlede malerier, catalogue raisonné. Oslo: Cappelen Damm; 2008

9. Topalova-Casadiego B. Tekniske aspekter ved Edvard Munchs malerier. In: Woll G, editor. Edvard Munch, samlede malerier, catalogue raisonné. 2 1898-1908. Oslo: Cappelen Damm; 2008. p. 425-58.

10. Plahter L. NG.M.00470 Condition Report. The National Museum of Art Norway., Conservation; 1982. Report No.: NG.M.00470_TR_1982_LEP.

11. Carlyle L, Bourdeau J. Varnishes: authenticity and permanence: workshop handbook. Ottawa: Canadian Heritage, Canadian Conservation Institute CCl; 1994.

12. Plahter LE. Ferniss i historisk perspektiv. In: Rød J, editor. Ferniss-seminar 1990. Nasjonalgalleriet, Oslo: Nordisk konservator forbund; 1990. p. 3-23.

13. Feller RL, Stolow N, Jones EH. On picture varnishes and their solvents. Washington: National Gallery of Art; 1985.

14. Phenix A, Townsend J. A brief survey of historical varnishes. In: Stonor JH, Rushfield R, editors. Conservation of easel paintings. Routledge: London; 2012. p. 252-63.

15. Colombini MP, Modugno F. Organic mass spectrometry in art and archaeology. Chichester: Wiley; 2009.

16. Varella EA, editor. Conservation science for the cultural heritage: applications of instrumental analysis. Berlin: Springer; 2013.

17. Derrick M. Fourier transform infrared spectral analysis of natural resins used in furniture finishes. J Am Inst Conserv. 1989;28(1):43-56.

18. Stuart B. Infrared spectroscopy: fundamentals and applications. Chichester:Wiley; 2004.

19. Arrizabalaga I, Gomez-Laserna O, Aramendia J, Arana G, Madariaga JM Applicability of a diffuse reflectance infrared fourier transform handheld spectrometer to perform in situ analyses on cultural heritage materials. Spectrochim Acta Part A Mol Biomol Spectrosc. 2014;129:259.

20. Miliani C, Rosi F, Daveri A, Brunetti B. Reflection infrared spectroscopy for the non-invasive in situ study of artists' pigments. Mater Sci Process. 2012;106(2):295-307.

21. Miliani C, Rosi F, Burnstock A, Brunetti BG, Sgamellotti A. Non-invasive in situ investigations versus micro-sampling: a comparative study on a Renoirs painting. Mater Sci Proces. 2007;89(4):849-56.
22. Thurmann-Moe J. NG.M.00485 Treament Report. The National Museum of Art, Norway, Conservation; 1954. Report No.: NG.M.00485_BR_1954_JTM.

23. Plahter L. NG.M.00394 Treatment Report. The National Museum of Art, Norway, Conservation; 1983. Report No.: NG.M.00394_BR_1983_LEP.

24. Plahter L. NG.M.01235B Treatment Report. The National Musem of Art, Norway, Conservation; 1983. Report No.: NG.M.01235B_TR_1983_LEP.

25. Dyer J, Verri G, Cupitt J. Multispectral imaging in reflectance and photoinduced luminescence modes: a user manual. London: The British Museum CHARISMA; 2013.

26. DeCruz A, Izatt J, Nankivil D. On the use of OCT to examine the varnish layer of paintings cleaned with an Er:YAG laser. In: Proceedings of the 4th international conference on photonics, optics and laser technology (PHOTOPTICS 2016); 2016.

27. Conservation archives. National Museum of Art, Oslo, Norway.

28. René De La Rie E, McGlinchey CW. The effect of a hindered amine light stabilizer on the ageing of dammar and mastic varnish in an environment free of ultraviolet light. Stud Conserv. 1990;35(1):160-4.

29. Doménech-Carbó MT, Doménech-Carbó A, Gimeno-Adelantado $J V$, Bosch-Reig F. Identification of synthetic resins used in works of art by fourier transform infrared spectroscopy. Appl Spectrosc. 2001;55(12):1590-602.

30. Sutherland K. Solvent-extractable components of linseed oil paint films. Stud Conserv. 2003:48(2):111-35.

31. Doncea SM, lon RM. FTIR (DRIFT) analysis of some printing inks from 19th and 20th centuries. Revue Roumaine de Chimie. 2014;59(3-4):173-83.

32. A summary of ultra-violet fluorescent materials relevant to conservation. AICCM. 2017. https://aiccm.org.au/national-news/summary-ultra-viole t-fluorescent-materials-relevant-conservation. Accessed 11 Aug 2019.

33. Manfredi M, Barberis E, Rava A, Robotti E, Gosetti F, Marengo E. Portable diffuse reflectance infrared Fourier transform (DRIFT) technique for the non-invasive identification of canvas ground: IR spectra reference collection. Anal Methods. 2015;7(6):2313-22.

34. Plahter L. Beneath the surface of Edvard Munch. In: Skaug E, HanssenBauer F, Kollandsrud K, editors. Conservare necesse est: festskrift til Leif Einar Plahter på hans 70-årsdag = for Leif Einar Plahter on his 70ieth birthday. Oslo: Nordisk Konservatorforbund, Den norske seksjon, IICNordic Group; 1999. p. 111-27.

\section{Publisher's Note}

Springer Nature remains neutral with regard to jurisdictional claims in published maps and institutional affiliations.

\section{Submit your manuscript to a SpringerOpen ${ }^{\odot}$ journal and benefit from:}

- Convenient online submission

- Rigorous peer review

- Open access: articles freely available online

- High visibility within the field

- Retaining the copyright to your article

Submit your next manuscript at $\gg$ springeropen.com 